\title{
Positive Importance of Arbuscular Mycorrhizal Fungi for Global Sustainable Agriculture and Environment Management for Green Technology
}

\author{
Kamal Prasad* \\ Warkem Biotech Pvt. Limited, Agro Division, B-508, Swastik Disha Business Parks, Via. Vadhani Industrial Estate, India \\ *Corresponding author: Kamal Prasad, Warkem Biotech Pvt. Limited, Agro Division, B-508, Swastik Disha Business Parks, Via. Vadhani \\ Industrial Estate, LBS Marg, Mumbai- 400086, Maharashtra, India
}

\begin{abstract}
Arbuscular mycorrhizal fungi (AMF) are the most common symbiotic association with most of the plants. AM fungi provide a range of important ecological services; in particular by enhance nutrition, stress resistance, tolerance, soil structure, pollution control and fertility. AM fungi interact with cereals, pulses, vegetables, and fruit trees; therefore, they receive increasing attention for their potential use in sustainable agriculture. Research of the past decade has revealed the existence of a dedicated recognition and signaling pathway that is required for AMF. Furthermore, recent evidence provided new insight into the exchange of nutritional benefits between the symbiotic partners. The great potential for application of AMF has given rise to a blossoming agricultural industry for agriculture, horticulture, landscaping, wasteland reclamations and pollution control for sustainable global development.
\end{abstract}

Keywords: AM Fungi; Agricultural; Sustainability; Symbiosis; Environment

\section{Introduction}

Sustainable agricultural farming are intended to protect the environment, expand the earth's natural resource, maintain and improve soil fertility and meeting society's food and textile needs, without compromising the ability for current or future generations to meet their basic needs. Currently several technologies increase yield in agriculture through sustainability ways. Sustainable agriculture provides a potential solution to enable agricultural systems to feed a growing population within the changing environmental conditions. Food and nutrition security has one of the greatest challenges for humanity and given existing population growth and climate change scenarios. Current estimates predict the need to increase agricultural productivity by at least $70 \%$ by 2050 , and the focus shifts increasingly to the role of soil biodiversity in general (Bender et al., [1]) and particularly AM fungi (Thirkell et al.,[2]; Prasad, [3]) in achieving this in a sustainable technique. AMF are widespread group of fungi that form a mutualistic relationship with land plants, including numerous agricultural crops known their ability to increase plant nutrient uptake and productivity (Prasad, [3]). In this article, discuss new developments in these fields, and highlight future potential toward the use of AM fungi for enhancement of agricultural crops in diverse environmental conditions for sustainable development.

AMF and Potential Impact: AM fungi form a mutually beneficial relationship with living roots of plants. They provide nutrition to plants by sequestering nutrients from the soil and chanelling them to the roots morphology. AMF infected plants has utilization of nutrients in highly efficient. Thus in the presence of sufficient amounts of mycorrhiza, plants exhibit a significant increase in growth rate, tolerance against biotic and abiotic stresses, as well as increased seedling survival and yield along with phosphorus solubilizing bacteria, many free-living nitrogen-fixing organisms and rhizobium work much more efficiently. These fungi therefore improve soil fertility and improve soil structure. AM fungi are naturally present in most soils, the number that is essential to 
achieve better plant production and soil restoration has decreased dramatically over the years due to excessive use of chemical fertilizers, insecticides, fungicides and pesticides.

\section{AM fungi and Soil Fertility}

AM fungal component involves within the cell of the root and the extraradical mycelium in the soil. Its primary function is the absorption of resources from the soil. The increased efficiency of AMF roots is caused by the active uptake and transport of nutrients by AMF. Generally AMF are improving the absorption of several nutrients such as $\mathrm{P}, \mathrm{N}, \mathrm{K}, \mathrm{Mg}, \mathrm{Cu}, \mathrm{Zn}, \mathrm{Ca}$, cadmium, nickel etc. AM fungi have been shown to improve productivity in soils of low fertility (Prasad, [3], Campo et al. [4]) and are particularly important for increasing the uptake of slowly diffusing ions (Johnson et al., [5]) immobile nutrients such as $\mathrm{P}, \mathrm{Zn}$ and $\mathrm{Cu}$ (Liu et al., [6]) and other nutrients such a Cadmium Guo et al.,

\section{AM Fungi and Phosphorus}

The AM fungi advantages are greatest in systems, there inputs are low. Heavy usage of phosphorus fertilizer can inhibit mycorrhizal colonization and growth. As the soil's phosphorus levels available to the plants increases, the amount of phosphorus also increases in the plant's tissues and carbon drain on the plant by the AM fungi symbiosis become non-beneficial to the plant (Grant et al., [7], Prasad [3]).

\section{AMF and Nitrogen}

Nitrogen $(\mathrm{N})$ applied in agricultural fields can be lost via leaching or in form of gaseous emissions. As for leachate $\mathrm{N}$, it occurs mostly in form of dissolved nitrate (NO3-), a particularly mobile form of $\mathrm{N}$ in soil. AM fungi promote soil aggregation (Leifheit et al., [8]) by improving soil structure and therefore increasing soil water-holding capacity. Moreover, AM fungi take up N preferentially in the form of ammonium (NH4+), reducing the pool of $\mathrm{N}$ available for nitrification and consequently reducing the mobility of $\mathrm{N}$.

\section{AM Fungi and Soil Quality, Yields and Reduce Expenses}

Better crop yields depend on good soil nutrient management. Farmers trust on nutrient inputs to manage soil nutrients. However, many organic and sustainable farmers also work to enhance natural biological processes in the soil in order to provide the nutrients crops need to thrive. Many of these biological processes are powered by mutually beneficial relationships (symbioses) that develop between plants and beneficial soil microbes. One of the most important of these symbioses develops between plant roots and fungi, producing structures called mycorrhizas. There are several types of mycorrhizal fungi, but the most important mycorrhizas are arbuscular mycorrhizal fungi. AM fungi are producing microscopic tree-like structures (arbuscules) and vesicles within cells of the plant's root. AM fungi are found naturally in most soils in worldwide. AM fungi improve soil quality, increase crop yield and reduce expenses in respect to chemical fertilizers.

\section{AM Fungi and Biocontrol Agent}

The AM fungi decrease diseases incidence systematically in plants. There is a localized specific influence of AM fungi on various alterations in host plants physiology. AM fungi enhance root growth, increase the absorption capacity and affect cellular processes on roots. The increased root growth and phosphate level of the plant may be responsible for increases tolerance of mycorrhizal plants towards pathogens by increasing the uptake of essential nutrients other than P that would be deficient in non mycorrhizal plants. Enhanced nutritional status of the plant by AM fungal colonization may affect qualitative and quantitative changes in root exudates to alter rhizosphere or rhizoplane microbial population. The role of mycorrhizae as biological control deterrents to feeder root infection by pathogens are an important of our understanding of the overall ecological significance of mycorrhizae (Prasad, Prasad and Bilgrami, [9,10], Prasad et al., [11]).

\section{AMF and Food Security}

With increasing populations and climate change, assuring food and nutrition security are an increasingly challenging task in worldwide. Climate smart and sustainable agriculture, that is, conceiving agriculture to be resistant and resilient to a changing climate while keeping it viable in the long term, is probably the best solution. The roles of AM fungi in new agriculture are believed to be of paramount importance. However, the large nutrient pools and the micro biota of soils are rarely considered in the equation. The potential contributions of AM fungi are more efficient fertilization, carbon sequestration, and reduction of greenhouse gas emissions in agriculture. The practice of crop rotations and cover cropping with deep rooting mycorrhizal plants, and low disturbance management, help fostering AM fungi communities for increase crop productivity to help food security.

\section{AMF and Renaturation and Reforestation}

Renaturation and afforestation are measures to stabilize degraded and eroding fields. In arid regions, young trees are very vulnerable to abiotic stresses (drought, heat, nutrient starvation); in early stages until they have established a deep root system that allows them to access ground water eserves. This critical phase can be overcome with AMF inoculation of the trees before planting.

\section{AMF and Bioremediation of Contaminated Soils}

During the last decades, the potential of plants has been explored to reduce the contamination of soils polluted by organic compounds or heavy metals. AM fungi could potentially play a crucial role in such strategies (Sheoran et al., [12]). AM fungi can 
potentially promote plant growth in contaminated soils, a capacity commonly referred to as bioremediation (Gohre and Paszkowski, [13]) and AM colonization is often reduced by high pollution.

\section{AMF and Greenhouse Gas Emission in Agriculture}

Modern agriculture is responsible for around $12 \%$ of the global anthropogenic greenhouse gas emissions (Linquist et al., [14]). Some of these emissions are associated with fertilizer production and the use of heavy machinery, but most of them occur in the form of direct emissions from the field. The potential benefits of AM fungi in alleviating emissions related to fertilizer application. AM fungi are reducing the release of carbon dioxide and nitrous oxide greenhouse gasses associated with agriculture.

\section{AMF and Commercial Usage}

The current scenarios, numerous benefits of AM fungi have raised opportunities for their commercial application. Consequently, the AMF related markets grew considerably during the past decades, with increasing numbers of products and marketing in worldwide for organic farming.

\section{Conclusions and Future Opportunities of AMF}

AM fungi encourage many aspects of plant life. AM fungi are improved nutrition, better growth, productivity, stress tolerance, and disease resistance. The hyphal networks of AM fungi improve soil structures such as soil particle aggregation thereby improving the resistance of soil toward erosion by wind and water. AM fungi decrease nutrient leaching from the soil, thereby contributing to the retention of nutrients in the soil, and decreasing the risks of contamination of ground water. These multiple benefits of AM fungi translate into significant ecological services in natural contexts. The AMF promises for agriculture have been clearly indicates in various agricultural, horticulture, wasteland development, landscaping to sustainable for green technology.

\section{References}

1. Bender SF, Wagg C, van der Heijden MGA (2016) An underground revolution: biodiversity and soil ecological engineering for agricultural sustainability. Trends Ecol Evol 20: 1-13.
2. Thirkell TJ, Charters AJ, Elliot SM, Sait, K J Field (2017) Are mycorrhizal fungi our sustainable saviour's considerations for achieving food security? J Ecol 105: 921-929.

3. Prasad K(2017) Biology, Diversity and promising role of mycorrhizal entophytes for green technology. In: Maheshwari DK (ed.) Endophytes: Biology and Biotechnology, Volume 1, Series Sustainable Development and Biodiversity 15. Springer International Publishing AG, Switzerland 267- 301.

4. Campo S, Martin-Cardoso H, Olive M (2020) Effect of Root colonization by arbuscular mycorrhizal fungi on growth, productivity and blast resistance in Rice. Rice 13: 42.

5. Johnson NC, Tilman D, Wedin D (1992) Plant and soil controls on mycorrhizal fungal Communities. Ecology 73: 2034-2042.

6. HamelC, Elmi A, Costa C, Ma B, Smith DL (2002) Concentrations of K, Ca and $\mathrm{Mg}$ in maize colonised by arbuscular mycorrhizal fungi under field conditions. Can J Soil Sci 82(3): 271-278.

7. Grant CS, Bitman Montreal M, Plenchette C, Morel C (2005) Soil and fertilizer phosphorus: effects on plant supply and mycorrhizal development. Canadian Journal of Plant Science 85: 3-14.

8. Grant CS, Bitman Montreal M, Plenchette C, Morel C (2005) Soil and fertilizer phosphorus: effects on plant supply and mycorrhizal development. Canadian Journal of Plant Science 85: 3-14.

9. Prasad K (1998) Biological control of rhizospheric microflora of Saccharum officinarum L. plant through vesicular arbuscular mycorrhizal (Glomus fasciculatum) fungi. Biome 8(1-2): 131-136.

10. Prasad K, Bilgrami RS (2009) Interaction between arbuscular mycorrhizal fungus (Glomus fasciculatum) and rhizospheric fungi in Saccharum officinarum L. Amravati University Research Journal, IV (2): 7-16.

11. Prasad K, Warke RV, Khadke K (2019) Management of soilborne pathogens to improve productivity of pulses using organic technologies for sustainable agriculture. International Journal of Research and Analytical Reviews 6(2): 82-101.

12. Sheoran V, Sheoran AS, Poonia P (2010) Soil reclamation of abandoned mine land by revegetation: a review. Int J Soil Sediment Water 3:13.

13. Gohre V, Paszkowski U (2006) Contribution of the arbuscular mycorrhizal symbiosis to heavy metal phytoremediation. Planta 223: 1115-1122.

14. Linquist B, Van Groenigen KJ, Adviento-Borbe MA, Pittelkow C, Van Kessel C (2012) An agronomic assessment of greenhouse gas emissions from major cereal crops. Glob Chang. Biol 18: 194-209.
This work is licensed under Creative Commons Attribution 4.0 License

To Submit Your Article Click Here:

Submit Article

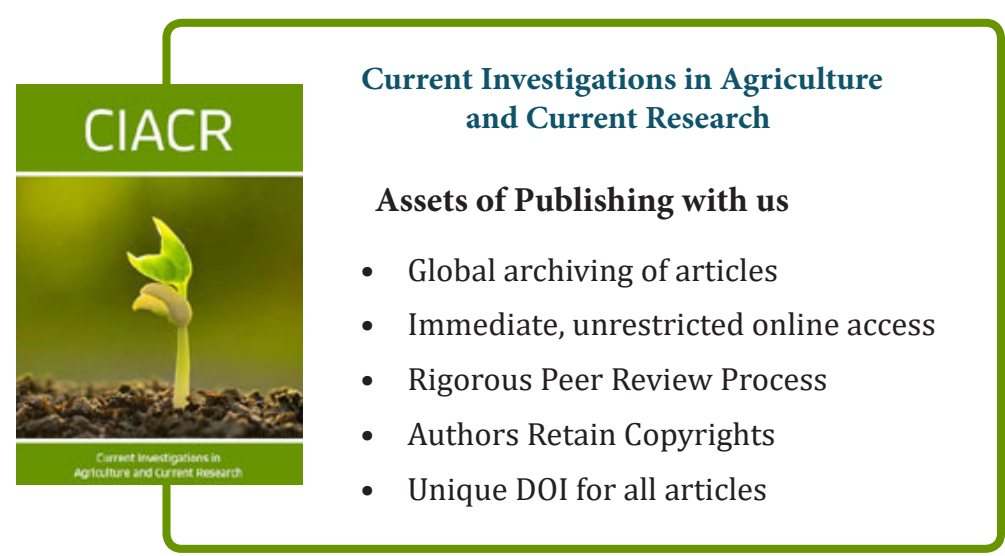

